\title{
Desafios no ensino da física
}

\author{
Challenges in physics teaching
}

\author{
Marco Antonio Moreira*1] \\ ${ }^{1}$ Universidade do Rio Grande do Sul, Porto Alegre, RS, Brasil
}

Recebido em 23 de outubro de 2020. Aceito em 25 de outubro de 2020.

\begin{abstract}
Aspectos didáticos conhecidos são abordados, neste texto, como desafiadores no ensino da Física porque não fazem parte desse ensino, mas deveriam estar sempre presentes. O ensino da Física é muito focado na aprendizagem mecânica, na preparação para as provas, mas deveria se ocupar da aprendizagem significativa da Física. Ao longo do texto são abordados tópicos como conceitos e conceitualização, situações que façam sentido, modelos e modelagem, competências científicas, laboratórios virtuais, aprendizagem significativa, dialogicidade e criticidade, interesse, sempre buscando um outro ensino da Física.

Palavras-chave: Ensino da Física; Desafios; Ensino para testagem.
\end{abstract}

Well known didactical aspects are approached, in this text, as challenges in the teaching of physics because they are not part of this teaching, but they should be. The teaching of physics focuses on rote learning, on the preparation for testing, but it should be focused on the meaningful learning of physics contents. Topics such as concepts and conceptualization, meaningful situations, models and modelling, scientific competences, meaningful learning, dialogicity and criticity, and interest are approached always looking for a different physics teaching.

Keywords: Physics teaching; Challenges; Teaching for testing.

\section{Introdução}

Provavelmente, o título deste trabalho sugere que estará focado no uso das Tecnologias Digitais de Informação e Comunicação (TDiCs). De fato, a incorporação dessas tecnologias no ensino da Física é um desafio, assim como para o ensino de muitas outras disciplinas.

No entanto, este artigo tratará de vários outros desafios, até mesmo antigos desafios, ou permanentes desafios, no ensino da Física, refletindo a experiência do autor no ensino de ciências/Física. Essa experiência inclui cinquenta anos como professor de Física na educação básica e superior sem nunca ter deixado a sala de aulas. Inclui também muitas coordenações, editorias, orientações de mestrado e doutorado, publicações na área de ensino de ciências, particularmente Física.

Mas por que ocupar-se de desafios para o ensino da Física? Porque esse ensino é muito problemático. Porque os alunos não aprendem Física significativamente. Memorizam mecanicamente fórmulas, definições, respostas certas, para serem reproduzidas nas provas e esquecidas logo depois.

Vivemos na cultura do ensino para a testagem, conhecido internacionalmente como teaching for testing. As escolas funcionam mais como centros de treinamento do que como centros educacionais e professores ${ }^{1}$ e alunos têm que se submeter a essa cultura treinadora que tem

\footnotetext{
* Endereço de correspondência: moreira@if.ufrgs.br

1 Os termos professor e aluno serão usados neste texto sem nenhuma alusão a gênero.
}

por trás a preparação para o mercado.

Desde que entram na educação básica os alunos começam a ser treinados para dar respostas corretas nas provas. Passar doze anos preparando alunos para provas é um absurdo, mas é comum na cultura do ensino para a testagem.

Obviamente, professores educadores não devem concordar com isso e não podem perder a esperança de que essa cultura seja modificada e que a educação seja voltada para a cidadania.

Neste texto serão abordados vários desafios para que o ensino da Física se afaste do ensino para provas. Aprender Física não é decorar fórmulas para resolver problemas ou definições e leis para dar respostas corretas nas provas. É muito mais do que isso.

Ensinar e aprender Física envolve conceitos e conceitualização, modelos e modelagem, atividades experimentais, competências científicas, situações que façam sentido, aprendizagem significativa, dialogicidade e criticidade, interesse, tópicos que serão abordados nas próximas seções, vários dos quais apesar de não serem novos se constituem em desafios para o ensino da Física.

\section{Conceitos e Conceitualização}

Para Stephin Toulmin [1], um conhecido epistemólogo, a chave da compreensão humana está nos conceitos [2]. Sem conceitos não compreendemos nada, conceitos estão na essência do desenvolvimento cognitivo. Disciplinas 
têm conceitos estruturantes sem os quais não existiriam. Por exemplo, os conceitos de quantum e de estado quântico na Mecânica Quântica, os conceitos de campo eletromagnético e força eletromagnética no Eletromagnetismo.

No ensino da Física é mais importante dar atenção aos conceitos físicos do que às fórmulas. As fórmulas contêm conceitos. Não tem sentido decorar fórmulas sem entender os conceitos que as constituem.

Do ponto de vista cognitivo, segundo Gérard Vergnaud [3], referência em psicologia educacional, a conceitualização é o núcleo do desenvolvimento cognitivo, ou seja, o ser humano vai se desenvolvendo cognitivamente à medida que vai conceitualizando, construindo conceitos 4.

Se o ensino da Física der mais atenção aos conceitos físicos do que ao formalismo matemático estará contribuindo para uma maior compreensão da Física e para o desenvolvimento cognitivo dos estudantes.

\section{Situações que Façam Sentido}

Foi dito que conceitos estão na base da compreensão humana, que são estruturantes de corpos de conhecimento e que a conceitualização é o núcleo do desenvolvimento cognitivo. Tudo isso deixa clara a importância dos conceitos no processo de ensino e aprendizagem da Física. Mas ainda não foi mencionada uma variável fundamental, a das situações. São as situações que dão sentido aos conceitos 3. Para serem aprendidos significativamente, novos conhecimentos devem fazer sentido para o aprendiz $2^{2}$ As situações devem ser propostas em níveis crescentes de complexidade e abstração. As primeiras situações devem ser do entorno de aluno. Parecem asserções óbvias, mas, usualmente, não são levadas em consideração no ensino de Física. É comum começar o ensino da Física com situações que não fazem sentido para os alunos e, muitas vezes, em níveis de abstração e complexidade acima de suas capacidades cognitivas. É nesse começo que o ensino da Física "perde" os alunos que, por sua vez, começam a não gostar da Física.

Isso ocorre também no ensino superior nas disciplinas de Física Geral. Nas Engenharias, por exemplo, a Física é ensinada sem usar situações da Engenharia. Um erro didático que leva os estudantes, futuros engenheiros, a estudarem Física apenas para "passar", para verem-se livres das disciplinas de Física Geral. Um verdadeiro absurdo.

\section{Modelos e Modelagem}

Outro erro no ensino de Física é não dar importância a modelos e modelagem. As chamadas ciências exatas,

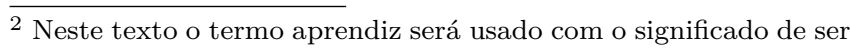
humano que aprende. como a Física, não são exatas, são aproximadas, pois dependem de modelos científicos e estes dependem das aproximações feitas, de como são controladas as variáveis. Na visão epistemológica de Mario Bunge [5, 6], toda a teoria física encerra um aspecto idealizado de um pedaço da realidade e essa idealização é chamada de modelo.

Essa visão epistemológica é clássica e bem aceita no contexto científico. O conhecimento científico é construído, modelos científicos são construídos, teorias científicas são construídas a partir desses modelos. Toda essa construção começa com um modelo conceitual de um fenômeno de interesse, de uma situação problema. Esse modelo pode evoluir teórica e matematicamente e chegar a uma teoria, cuja aceitação (que é sempre provisória), refutação (que pode ser definitiva) ou revisão (introdução de modificações para melhorá-la) depende da experimentação [7].

A argumentação de que modelos são aproximados e que as teorias físicas não são definitivas em nenhum momento significa minimizar o papel de modelos e teorias na construção do conhecimento físico. Ao contrário, são de alta relevância e estão na base da tecnologia, mas contêm aproximações e podem sofrer modificações, correções ou substituições.

Ensinar Física como ciência exata e cheia de teorias definitivas, acabadas, é um erro epistemológico. Ensinála como em permanente construção é um desafio epistemológico.

Cabe aqui fazer uma certa analogia com a construção cognitiva: para querer resolver uma situação-problema a primeira coisa que um ser humano faz é construir um modelo mental [8 na memória de trabalho. Esse modelo pode começar como um modelo caixa-preta, pode ser abandonado se não for funcional, mas pode ser modificado e evoluir, se funcionar, até um esquema de assimilação com o qual o indivíduo dá conta de um conjunto de situações. Essa é a modelagem mental.

Na Física, modelos conceituais e teóricos são construídos como instrumentos para a compreensão de fenômenos físicos, enquanto que modelos mentais são os que as pessoas realmente têm em suas cabeças e o que guia suas ações $[9$.

Há uma clara analogia entre a modelagem mental e a modelagem científica. Essa analogia leva a uma pergunta: é possível usar a modelagem no ensino de sistemas físicos? Certamente! A modelagem computacional e a modelagem matemática têm muito potencial. Ao invés de o aluno ser incentivado a "achar" uma fórmula para resolver uma situação-problema, por que não construir um modelo computacional para essa situação-problema? Os alunos de hoje vivem no mundo das tecnologias digitais de informação e comunicação e seguramente se sentiriam motivados na construção de modelos computacionais. O problema é que a modelagem computacional não encaixa no ensino para a testagem, modelos computacionais "não caem nas provas". 
A modelagem matemática é o processo que envolve a construção de um modelo matemático que é um conjunto de símbolos e relações matemáticas que procura traduzir, de alguma forma, um fenômeno em questão ou problema de situação real [10, p. 12]. A modelagem matemática está sempre presente na construção de teorias científicas, em particular de teorias físicas. Então, essa modelagem deveria estar sempre presente, em alguma medida, no ensino da Física. Mas isso não acontece. Modelos matemáticos não fazem parte da preparação para a testagem. Fórmulas prontas, memorizadas mecanicamente, sim. E são valorizadas a tal ponto que a Física é percebida pelos alunos como um conjunto de fórmulas. Essa percepção distorce o papel da Matemática na Física.

\section{Competências Científicas}

Competência é um conceito antigo, vindo do mundo laboral e tinha a ver com habilidades práticas. Com o advento do behaviorismo, o significado de competência ficou muito associado a objetivos comportamentais. Mais recentemente, ficou de moda o currículo por competências e defensores desse currículo dizem que não é um currículo comportamentalista.

Mas, no caso do ensino da Física, quais seriam as competências? Por exemplo, modelagem científica, argumentação baseada em evidências, comunicação de resultados, perguntar, questionar e criticar cientificamente.

$\mathrm{Na}$ ótica de Perrenoud [11, um renomado autor no campo das competências, conhecimentos e competências são complementares, não tem sentido adquirir conhecimentos sem competências e, vice-versa, não tem sentido ter competências sem conhecimentos. Há uma relação dialética entre conhecimentos e competências, mas no ensino da Física competências científicas são ignoradas, o foco fica em conteúdos a serem decorados mecanicamente e reproduzidos nas provas.

\section{Laboratórios Virtuais}

É normal distinguir entre Física Teórica e Física Experimental, mas são complementares. Como já foi dito, modelos teóricos são validados, confirmados, revisados ou refutados, a partir da experimentação. Por outro lado, não tem sentido a experimentação isolada sem ter nada a ver com a teorização.

No ensino da Física essa complementaridade é essencial para uma aprendizagem significativa dos conteúdos físicos. Mas, na prática, esse ensino é conduzido sem atividades experimentais, segue o modelo expositivo no qual o professor "dá a matéria" para os alunos anotarem em seus cadernos ou fotografarem com seus celulares. Um grande erro um ensino de Física sem atividades experimentais. A "justificativa" é que a escola não tem laboratório. Mas nem sempre é assim, é comum que laboratórios existam nas escolas e permaneçam fechados, não sejam usados.

Como poderia ser resolvido esse problema? Com laboratórios virtuais! Cada vez mais os alunos têm acesso a computadores e internet, na escola ou em casa. Em laboratórios virtuais os alunos podem fazer simulações, construir modelos computacionais, alterar variáveis em modelos preexistentes para ver o que acontece, fazer experimentos remotos. Enfim, podem aprender Física e desenvolver competências científicas. Celulares também têm potencial para o desenvolvimento de atividades experimentais no ensino da Física.

Mas, então, por que o ensino de Física continua no modelo tradicional sem atividades experimentais? Porque a experimentação não se enquadra no ensino para a testagem, é "perda de tempo", pois nesse ensino o importante é abordar todo o conteúdo da disciplina e ensinar respostas corretas a serem dadas nas provas.

\section{Aprendizagem Significativa}

A aprendizagem mecânica, criticada em itens anteriores deste texto é aquela em que há, na estrutura cognitiva, um armazenamento de conhecimentos de forma literal, arbitrária, sem significados, que não requer compreensão e resulta em aplicação mecânica a situações conhecidas. Contrariamente, na aprendizagem significativa há uma incorporação de conhecimentos à estrutura cognitiva de forma substantiva, não arbitrária, com significado, com compreensão, com capacidades de explicação, descrição e transferência desses conhecimentos, inclusive a situações novas.

Mas não se trata de uma dicotomia, quer dizer, a aprendizagem não é ou mecânica ou significativa. Aprendizagem mecânica e a aprendizagem significativa são extremos de um contínuo. Entre elas há uma "zona cinza" na qual, em sala de aulas, por exemplo, pode estar ocorrendo aprendizagem significativa em razão do ensino recebido, dos materiais instrucionais e das atividades desenvolvidas. A aprendizagem significativa não é abrupta, é progressiva, os conhecimentos vão sendo adquiridos, progressivamente, com significados aceitos no contexto da matéria de ensino.

O problema dessa progressividade é que no ensino para a testagem ela praticamente não ocorre, a aprendizagem fica muito próxima da mecânica e longe da significativa. Aprender "respostas corretas", sem compreensão, para apresentá-las nas provas, é aprendizagem mecânica. Decorar fórmulas, sem entendê-las, para aplicá-las em problemas conhecidos é também aprendizagem mecânica. É o mais comum no ensino da Física, ou seja, um ensino que estimula a aprendizagem mecânica de fórmulas, definições, leis, respostas, para usá-las, e passar, nas provas, esquecendo tudo pouco tempo depois. Não é exagero, grande parte do ensino da Física na educação básica e superior assim, no Brasil e no exterior. Um ensino pior do que ineficaz, é anticientífico, como 
disse Carl Wieman 12 físico ganhador do Nobel de Física em 2001 e muito atuante no ensino da Física.

\section{Condições de Ocorrência}

Mas quais seriam as condições de ocorrência da aprendizagem significativa? Segundo David Ausubel [13], a maior referência internacional em aprendizagem significativa, são duas condições: o conhecimento prévio de quem aprende e sua predisposição para aprender. Em linguagem informal, poder-se-ia dizer que como seres humanos aprendemos a partir do que já sabemos e aprendemos se queremos.

Por conhecimento prévio entende-se conceitos, proposições, modelos, concepções, crenças, enfim, o que já existe na estrutura cognitiva de quem aprende e pode funcionar como precursor de novos conhecimentos ou como obstáculo epistemológico. Conhecimentos prévios que servem como "ancoradouro" cognitivo para dar significado a novos conhecimentos, em um processo interativo, são chamados conceitos subsunçores, mas não são necessariamente conceitos. Por isso, é melhor chamá-los apenas de subsunçores. O termo ancoradouro é metafórico, ou seja, subsunçores funcionam como se fossem ancoradouros, mas o processo é interativo e nessa interação o subsunçor pode se modificar, adquirir novos significados, ficar mais rico, mais diferenciado, mais estável e ainda mais capaz de ancorar (dar significados) a novos conhecimentos.

Por exemplo, se o aluno já tem o conceito de campo gravitacional ele pode servir como subsunçor para a aprendizagem significativa do conceito de campo eletromagnético. Mas este pode ser elétrico ou magnético e as forças podem ser atrativas ou repulsivas enquanto que a gravitacional é sempre atrativa. Então, nessa subsunção o conceito de campo gravitacional não se modifica, mas o conceito de campo sim, pois fica diferenciado, podendo ser gravitacional ou eletromagnético (elétrico ou magnético). Mais adiante, esse "novo" conceito de campo pode funcionar como subsunçor para a aprendizagem significativa do campo nuclear, cuja força pode ser forte ou fraca. Ao longo desse processo, o conceito de campo vai ficando mais significativo, mais rico, diferenciado, estável, com espaço para outros campos como é o caso do recente campo de Higgs. Campo é um conceito central na Física e não se limita a uma "classificação" de campos (gravitacional eletromagnético, nuclear, Higgs...). É um conceito estruturante da Física. A aprendizagem significativa do conceito de campo na Física é muito mais importante do que decorar as fórmulas das Leis da Gravitação e de Coulomb.

Antes de passar a outra condição de ocorrência da aprendizagem significativa, a da predisposição para aprender, cabe esclarecer mais alguns aspectos da primeira. Conhecimento prévio não é o mesmo que prérequisito. Como já foi dito, conhecimento(s) prévio(s) é o que está na estrutura cognitiva, podendo servir como subsunçor ou obstáculo epistemológico. Pré-requisito é um conceito comportamentalista, é uma resposta condicionada que é condição para condicionar uma nova resposta.

Muitas vezes ao se falar em condições para ocorrência da aprendizagem significativa aparece: materiais instrucionais potencialmente significativos e predisposição para aprender. No fundo, as condições são as mesmas porque para que um material instrucional seja potencialmente significativo para quem aprende é preciso que disponha de conhecimentos prévios (subsunçores) adequados para dar significado aos conhecimentos que estão sendo trazidos através desse material. Não existe material instrucional significativo. O significado está sempre nas pessoas (alunos, professores) não nos materiais (livros, aplicativos, aulas,...). Por isso, usa-se o termo potencialmente significativo. É claro que os materiais devem ser de boa qualidade, devem ter significado lógico, mas o significado psicológico é atribuído pelo sujeito que aprende e este deve apresentar uma predisposição para aprender.

\section{A predisposição para Aprender}

A ideia básica é que para aprender significativamente determinado conhecimento o aprendiz deve manifestar uma disposição para relacionar, de maneira substantiva e não arbitrária, o novo material, potencialmente significativo, a sua estrutura cognitiva, deve ter uma intencionalidade.

$\mathrm{Na}$ prática, essa predisposição é muitas vezes confundida com motivação e é comum o argumento que os alunos estão desmotivados a aprender Física, não gostam de Física. Mas não é assim, a predisposição para aprender vai muito além de motivação. Tem tudo a ver com interesse, um tema que será abordado mais adiante neste texto. Despertar o interesse dos alunos é sempre um desafio no ensino da Física e de muitas outras disciplinas, se não todas, do currículo escolar.

\section{Dialogocidade e Criticidade}

Se o conhecimento prévio é uma variável fundamental para a aprendizagem significativa, é obvio que no início das aulas deve-se buscar informações sobre esse conhecimento prévio dos alunos. Como fazer isso? Pré-teste? É comum que seja feito, mas não adianta muito porque geralmente é um teste de múltipla escolha que só mede o número de respostas certas sem dar nenhuma informação relevante sobre o conhecimento prévio dos alunos em termos de significado, de compreensão.

É muito mais útil desenvolver atividades iniciais que levem os alunos a externalizarem seus conhecimentos prévios "certos ou errados" ou mesmo a ausência deles. Atividades desse tipo podem incluir mapas mentais, mapas conceituais, tarefas em pequenos grupos, discussões a partir de vídeos ou textos, tecnologias 
digitais de informação e comunicação. Sejam quais forem, o importante é que os alunos externalizem seus conhecimentos prévios.

É claro que será um desafio tentar levar em conta os conhecimentos prévios identificados nessas atividades. Mas ensinar buscando aprendizagem dos alunos é sempre um desafio. Ensinar sem levar em conta, em alguma medida, o conhecimento prévio dos alunos é um erro didático. Ensino sem aprendizagem não tem sentido.

Mas essa externalização de conhecimentos não pode ficar restrita a atividades iniciais, pois a aprendizagem significativa é progressiva. É preciso que o professor saiba se os alunos estão captando os significados dos conteúdos, declarativos e procedimentais, que estão sendo trabalhados nas aulas.

Segundo D.B. Gowin [14], em uma situação de ensino aprendizagem há uma relação triádica entre professor, materiais educativos e aluno, cujo objetivo é que o aluno venha a compartilhar os significados que são aceitos no contexto da matéria de ensino. Para isso, deve haver uma "negociação de significados". O aluno tem que externalizar os significados que está captando e o professor tem que verificar se são os esperados. Portanto, o ensino não pode ser monológico, tem que ser dialógico.

$\mathrm{Na}$ perspectiva de Paulo Freire [15], na educação dialógica, estudar requer apropriação da significação dos conteúdos, a busca de relações entre os conteúdos e entre eles e aspectos históricos sociais e culturais do conhecimento. Requer também que o educando se assuma como sujeito do ato de estudar e adote uma postura crítica e sistemática. Segundo Freire, a dialogicidade - essência da educação como prática da liberdade - é imprescindível. Nessa perspectiva freireana, a educação autêntica não se faz do educador para o educando ou do educador sobre o educando, mas do educador com o educando.

Ainda nessa perspectiva, a criticidade, a consciência critica, é fundamental em uma educação libertadora. Isso tem a ver com o que já foi dito antes quanto aos modelos e teorias físicas que não devem ser ensinadas como definitivas.

Voltando à aprendizagem significativa, sua ocorrência não implica que os conhecimentos adquiridos sejam únicos, definitivos. Aprendizagem significativa é aprendizagem com significado, com compreensão, mas isso não significa que não existam outros significados para o que está sendo aprendido. A captação de significados se refere aos que são aceitos no contexto da matéria de ensino. Aprender Física significativamente significa aprender conteúdos físicos, declarativos e procedimentais, tal como são aceitos no contexto da Física. Metaforicamente, é aprender a linguagem da Física, aprender a "falar Física". Pode ser uma linguagem maravilhosa, mas não é a única.

Poder-se-ia, então, pensar em uma aprendizagem significativa crítica [16], uma aprendizagem que implique pensar criticamente, aprender a aprender, rejeitar certezas, encarar o erro como natural e aprender através de sua superação. Este tipo de aprendizagem é antagônico ao da passividade estimulada pelo ensino focado nas provas, na testagem. Nesse ensino, o importante é memorizar, decorar, sem questionamento, as respostas corretas a serem dadas nas provas.

No ensino da Física, voltado à aprendizagem significativa crítica, os alunos devem participar ativamente, os materiais instrucionais devem ser diversificados, o questionamento deve ser estimulado, o conhecimento científico deve ser tratado como uma construção humana sempre em desenvolvimento, com consciência semântica (o significado está nas pessoas, não em objetos ou eventos). Uma aprendizagem para a vida, para a cidadania, não aquela tradicional que só serve para usar nas provas.

\section{Interesse}

Este é provavelmente o maior desafio do ensino da Física: o interesse. Como despertar nos alunos o interesse pela Física? É lugar comum que os alunos da educação básica não gostem da Física, chegando ao ponto de dizerem que "detestam" a Física e, até mesmo, que "odeiam" a Física. $\mathrm{Na}$ educação superior é comum que estudantes evitem carreiras que têm Física ou que cursem disciplinas de Física Geral porque são obrigatórias e só querem passar. O que fazer para mudar essa visão da Física, difícil, formulista, sem interesse para os alunos? Vejamos alguns significados de interesse.

Começando com John Dewey [17, há pouco mais de 100 anos atrás ele dizia que a palavra interesse sugere, etimologicamente, o que está entre, aquilo que conecta duas coisas que estariam distantes se não existisse. Na educação, essa distância muitas vezes é pensada como sendo uma questão de tempo, não dando atenção ao fato de que há muito o que superar entre um estágio inicial do processo e o período de sua finalização; há alguma coisa entre [17, p. 136].

$\mathrm{Na}$ aprendizagem, as capacidades iniciais do aprendiz constituem o estágio inicial; os objetivos do professor representam um limite remoto. Entre os dois está o meio, ou seja, condições intermediárias, ações a serem cumpridas, dificuldades a serem superadas, aplicações a serem feitas. Somente através delas é que atividades iniciais alcançarão uma consumação satisfatória [17]. Interesse significa que quem está aprendendo se identifica com os objetos de estudo que definem a atividade e fornecem meios e obstáculos a sua realização [17, p. 147]. Reconhecer a importância do interesse não significa que todas a mentes funcionam da mesma maneira só porque têm o mesmo professor e os mesmos materiais instrucionais [17, p. 139].

As colocações de Dewey têm muito a ver com a progressividade da aprendizagem significativa. Há muita coisa entre os conhecimentos prévios do aluno e a aprendizagem significativa de algum conteúdo, passando sempre pelo interesse, pelo que está entre. 
Praticamente cinquenta anos depois da publicação do livro de Dewey, Democracy and Education (1916), Ausubel e Robinson [18] publicaram em 1969 um livro, School Learning: An introduction to educational psychology, no qual diziam o seguinte: aprendizagem significativa (meaningful learning) pressupõe uma postura, uma direção, uma tendência (a meaningful learning set) para relacionar, não arbitrariamente e substantivamente, a tarefa de aprendizagem a sua estrutura cognitiva. Colocação muito coerente com o interesse de Dewey.

Recentemente Renninger, Nieswandt e Hidi [19], publicaram um livro, Interest in mathematics and science learning, especificamente sobre a importância do interesse na aprendizagem de matemática e ciências. Nas primeiras páginas destacam cinco características do interesse com as quais tendem a concordar todos que o estudam como uma variável pedagógica distinta [19, p. 1-2]:

1. interesse sempre se refere à interação com algum conteúdo em particular (e.g., matemática, ciências);

2. interesse existe em uma relação particular entre aprendiz e seu entorno;

3. interesse tem tanto componentes efetivos como cognitivos, apesar de que a influência de cada um varia dependendo da fase de desenvolvimento do interesse;

4. o aprendiz pode, ou não, estar consciente do que seu interesse foi despertado;

5. interesse funciona como uma recompensa que leva o aprendiz a procurar novos recursos e desafios.

Esses autores identificam quatro fases do desenvolvimento do interesse [19, p. 4]:

1. situacional despertadora;

2. situacional mantida;

3. situacional emergente;

4. interesse individual bem desenvolvido.

Nas fases iniciais do interesse (despertada e mantida) aprendizes necessitam de apoio para fazer conexões entre o mundo real e as tarefas de aprendizagem, enquanto que nas fases posteriores (interesse individual emergente $e$ bem desenvolvido) essas conexões estão feitas e os aprendizes estão prontos para trabalhar mais diretamente com desafios do conteúdo.

Interesse pode também ser interpretado em termos de uma emoção básica, de um tipo de afeto (tristeza, perda, fracasso, razão motivacional, expressão facial, maior compreensão,...) e/ou de um esquema cognitivo emocional (construto adquirido, altamente individualizado, cheio de satisfações, atribuições, conhecimentos, interpretações e cognições de ordem superior) [19, p. 80].

Outro aspecto fundamental da questão do interesse, destacado pelos autores [19, p. 166], é a integração autorregulação e interesse.
Autorregulação refere-se ao processo pelo qual estudantes sistematicamente focam seus pensamentos, sentimentos e ações, para alcançar metas de aprendizagem. Consiste em três outros processos: auto-observação (monitoramento), autojulgamento e autorreação. Autoobservação significa dar atenção a seu próprio comportamento; auto julgamento significa comparar o nível atual de desempenho com as metas individuais; autorreação significa responder cognitivamente, afetivamente e comportamentalmente ao seu próprio autojulgamento.

Ainda em relação ao interesse, os mesmos autores chamam atenção para outros conceitos importantes: motivação intrínseca, motivação extrínseca, autodeterminação e autoeficácia [19, p. 189]:

Motivação intrínseca refere-se à motivação para aprender algum tópico por sua própria causa, seu próprio fim.

Motivação extrínseca envolve aprender certo assunto como um meio de alcançar certo objetivo como, por exemplo, uma nota ou uma carreira.

Autodeterminação refere-se ao controle que estudantes acreditem ter sobre sua própria aprendizagem.

Autoeficácia é relativa à própria crença de ser capaz de aprender determinado assunto.

Cabe aqui destacar o conceito de auto eficácia [20: são julgamentos que fazemos sobre o quanto somos eficazes em determinadas situações. Essas avaliações de autoeficácia são importantes na determinação da escolha de uma atividade por parte de quem aprende e em influenciar a quantidade de interesse e esforço dispendidos.

\section{Ensino de Física e Interesse}

Quando foi abordada a teoria da aprendizagem significativa deve ter ficado claro que uma das condições fundamentais para sua ocorrência é a predisposição para aprender, a qual é comumente interpretada como motivação. No entanto, de tudo o que foi dito sobre o conceito de interesse, na seção interior, é fácil inferir que predisposição para aprender vai muito além de motivação.

Em termos de ensino e aprendizagem da Física é muito mais importante concentrar-se no interesse dos alunos. E aí vem um grande problema para o ensino da Física: por que grande parte dos alunos não se interessa pela Física? E um grande desafio: como despertar o interesse dos alunos pela Física?

Como dizia John Dewey, há muita coisa entre as condições iniciais dos alunos e os objetivos do ensino, passando por características e fases do interesse, autorregulação (auto-observação, autojulgamento e autorreação), autodeterminação e auto eficácia de parte dos alunos. Por que os alunos não tem interesse pela Física? Por que desistem de aprender Física significativamente e ficam na aprendizagem mecânica? Porque o ensino da Física não desperta seu interesse, porque os leva a uma autorregulação negativa, a uma fraca autodeterminação, 
a uma baixa autoeficácia. São pontos, para reflexão. O ensino da Física precisa ser repensado. A Física é uma herança humana. Aprender Física é um direito da cidadania e pode ser interessante, cativante. Mas para isso o ensino tradicional, formulístico, baseado na narrativa do professor e listas de problemas, tem que mudar.

\section{Conclusão}

Como foi dito na Introdução, o título deste trabalho sugere que seriam abordados desafios no ensino de Física relativos à contemporaneidade, ao mundo atual, às tecnologias digitais de informação e comunicação. Mas não é bem assim. É claro que há desafios nesse sentido, mas o ensino da Física tem que dar conta de vários desafios "antigos", "clássicos", se o objetivo for aprendizagem da Física com significado, compreensão e interesse.

A título de conclusão, são apresentados a seguir vários desafios no ensino da Física que podem ser inferidos dos tópicos abordados ao longo do texto, não necessariamente em ordem prioritária.

- Dar mais atenção a conceitos do que fórmulas; há conceitos que são estruturantes da Física; conceitos estão na base da compreensão humana; a conceitualização é o núcleo do desenvolvimento cognitivo.

- Usar situações que façam sentido para os alunos; são as situações que dão sentido aos conceitos; as primeiras situações devem ser do entorno do aluno; as situações devem ser propostas em níveis crescentes de complexidade e abstrações, mas devem fazer sentido para quem está aprendendo.

- Levar em conta o conhecimento prévio dos alunos o máximo possível; é uma variável fundamental para a aprendizagem de novos conhecimentos; pode funcionar como "ancoradouro" de novos conhecimentos ou como obstáculo epistemológico.

- Dar atenção a modelos e modelagem; as teorias físicas começam com modelos conceituais; modelos físicos contêm aproximações, não são exatos.

- Não ensinar as teorias físicas como definitivas e os princípios físicos como verdades; a Física é uma ciência em permanente construção; conceitos, princípios, modelos e teorias atuais são excelentes construções da Física, mas podem evoluir ou, eventualmente, serem abandonadas.

- Estimular o desenvolvimento de competências científicas como modelagem científica, argumentação baseada em evidências, comunicação de resultados, perguntar e questionar cientificamente. É muito mais importante desenvolver competências científicas do que decorar fórmulas e aplicá-las em situações conhecidas.

- Buscar um ensino híbrido com participação ativa dos alunos e do professor, centrado nos alunos e no professor; no processo ensino-aprendizagem educador e educando são igualmente importantes; não existe ensino sem aprendizagem.

- Incorporar as tecnologias digitais de informação e comunicação no ensino sem abandonar atividades presenciais, mantendo a interação social, a negociação de significados.

- Utilizar laboratórios virtuais; computadores e celulares fazem parte do entorno dos alunos; laboratórios virtuais podem ser usados em simulações, modelos computacionais, experimentos virtuais; a experimentação deve fazer parte do ensino da Física.

- Procurar sempre promover a aprendizagem significativa dos alunos; independente das estratégias didáticas e dos materiais instrucionais, considerar aprendizagem significativa como um paradigma.

- Na avaliação, buscar evidências de aprendizagem significativa; testes de múltipla escolha não avaliam, apenas medem a quantidade de respostas certas.

- Despertar o interesse dos alunos pela Fúsica. Este é o maior de todos os desafios no ensino da Física. O ensino focado na preparação para a testagem, no aplicacionismo de fórmulas, na memorização de respostas corretas, provoca desinteresse dos alunos. É uma perda de tempo.

O interesse, como deve ter ficado claro na abordagem feita, é um grande desafio para o ensino da Física. Mas vale a pena enfrentá-lo. A Física é importante na cidadania, está na base das tecnologias, é uma ciência exemplar. Não tem sentido ensinar Física sem despertar o interesse dos alunos. Esta é a mensagem final deste texto.

\section{Referências}

[1] S. Toulmin, La comprensión humana: El uso colectivo y la evolución de los conceptos (Alianza Editorial, Madrid, 1977), v. 1.

[2] M.A. Moreira e N.T. Massoni, Epistemologias do século XX (E.P.U., São Paulo, 2011).

[3] G. Vergnaud, Récherche en Didactique des Mathématiques 10, 133 (1990).

[4] M.A. Moreira, Investigações em Ensino de Ciências 7, 7 (2002).

[5] M. Bunge, La ciencia su método y su filosofía (Ediciones Siglo Veinte, Buenos Aires, 1960).

[6] M. Bunge, Teoria e realidade (Editora Perspectiva, São Paulo, 1974).

[7] M.A. Moreira, Revista Brasileira de Ensino de Ciências e Tecnologia 7, 159 (2014).

[8] P.J Johnson-Laird, Mental models (MA: Harvard University Press, Cambridge, 1983).

[9] D. Gentner e A.L. Stevens, Mental models (N.J.: Laurence Erlbaum Associates, Hillsdale, 1983).

[10] M.S. Biembengut, N. Hein, Modelagem matemática no ensino (Editora Contexto, São Paulo, 2003). 
[11] P. Perrenoud, Construir competências desde a escola (Artmed, Porto Alegre, 1999).

[12] J. Mervis, Science 340, 292 (2013).

[13] D.P. Ausubel, Aquisição e retenção de conhecimentos: uma perspectiva cognitiva (Plátano Edições Técnicas, Lisboa, 2003).

[14] D.B. Gowin, Educating (Cornell University Press, Ithaca, 1981).

[15] P. Freire, Pedagogia da Autonomia: saberes necessários à prática educativa (Paz e Terra, São Paulo, 2007), 36 ed.

[16] M.A. Moreira, Aprendizagem significativa crítica (Instituto de Física da UFRGS, Porto Alegre, 2005).

[17] J. Dewey, Democracy and Education. An introduction to the philosophy of education (Myers Education Press, Gorham, 2018), (First Ed., 1916).

[18] D.P. Ausubel e F.G. Robinson, School learning: An introduction to educational psychology (Holt, Rinehart \& Winston, 1969).

[19] K.A. Renninger, M. Nieswandt, e S. Hidi, Interest in mathematics and science learning (American Educational Research Association, Washington, 2015).

[20] A. Bandura, R.G. Azzi e S. Polydoro, Teoria Social Cognitiva: conceitos básicos (Artmed, Porto Alegre, 2008). 